\title{
SEMIOTIKA KOMUNIKASI PEMENTASAN \\ TARI BARIS KERARAS DALAM UPACARA ACI TULAK TUNGGUL DI PURA TAMAN AYUN DESA ADAT MENGWI
}

\author{
Dewa Putu Wahyu Kresna Purwanta $\underline{a, 1}$ \\ I Dewa Ayu Hendrawathy Putri a \\ I Ketut Wardana Yasa $\underline{a}$
}

a Universitas Hindu Negeri I Gusti Bagus Sugriwa Denpasar

1 Corresponding Author, email: dewapurwanta@gmail.com (Purwanta)

\section{ARTICLE INFO}

Article history:

Received: 10-07-2021

Revised:15-08-2021

Accepted: 14-09-2021

Published: 30-09-2021

Keywords:

Semiotika

Komunikasi, Tari

Baris Keraras, dan

Upacara

Aci Tulak Tunggul
ABSTRACT

\begin{abstract}
Baris Keraras Dance is a unique and sacred dance that is only found in Taman Ayun Temple, Mengwi Traditional Village in accordance with the original using traditional means. The formulation of the problem in this study is (1) how is the existence of the Baris Keraras Dance in the Aci Tulak Tunggul ceremony at Taman Ayun Temple? (2) how is the Semiotics of Communication in the performance of the Baris Keraras Dance in the Aci Tulak Tunggul ceremony? (3) What are the implications of performing the Baris Keraras Dance in the Aci Tulak Tunggul ceremony? This article borrows concepts and theories, such as religious theory, semiotics and symbolic interactionism. This study used qualitative research methods. Research finds. First, the existence of the Baris Keraras dance in the Aci Tulak Tunggul ceremony at Taman Ayun Temple is a tradition passed down from generation to generation from their ancestors, every Aci Tulak Tunggul ceremony at Taman Ayun Temple is equipped with a Baris Keraras dance performance. Second, regarding the performance of the Baris Keraras Dance in the Aci Tulak Tunggul ceremony at Taman Ayun Temple, Mengwi Traditional Village, Mengwi District, Badung Regency, there are several communication semiotics, namely (1) the Semiotics of the Baris Keraras Dance Performance, (2) Semiotics of the Aci Tulak Tunggul Ceremony, (3) Keraras Baris Dance Movement Semiotics, and (4) Keraras Baris Dance Costumes and Properties Semiotics. Third, the performance of the Baris Keraras Dance in the Aci Tulak Tunggul ceremony has implications: (1) Communication Implications, (2) Socio-Cultural Implications, (3) Sociological Implications, (4) Tri Hita Karana Implications, (5) Implications of the Balance of Bhuana Aauna and Bhuana Alit. and (6) Economic Imblications.
\end{abstract}

\section{PENDAHULUAN}

Komunikasi sangat penting dalam suatu kehidupan, karena tanpa adanya komunikasi manusia tidak bisa saling berinteraksi antara manusia dengan manusia, atau manusia dengan makhluk hidup. Keberadaan manusia sebagai makhluk sosial membuat manusia harus selalu berinteraksi antar sesama. Sebuah interaksi akan terjadi jika adanya komunikasi antar manusia yang satu dengan manusia yang lainnya. 
Komunikasi menjadi aspek yang sangat penting dalam kehidupan manusia, karena tanpa adanya komunikasi, interaksi sosial tidak akan pernah terjadi. Begitu pentingnya peran komunikasi dalam kehidupan manusia, sehingga membuat manusia selalu berkomunikasi dari bangun tidur kemudian melakukan aktivitas seharian dan sehingga kembali tidur.

Komunikasi sebagai salah satu aktivitas yang sangat diperlukan dalam kehidupan manusia. Komunikasi merupakan proses penyampaian pesan dari komunikator kepada komunikan dengan maksud untuk mengubah persepsi dan pemahaman komunikan. Sebuah komunikasi dikatakan efektif jika pemaknaan dari pesan yang disampaikan sama dengan pesan yang diterima oleh komunikan. Dalam perjalanan kehidupan manusia, komunikasi tidak hanya terjadi antar sesama manusia saja. Ternyata dalam proses komunikasi ada sejumlah simbol yang dapat disimbolkan oleh manusia, yang disebut dengan komunikasi simbol. Dalam komunikasi simbol belum begitu banyak dikemukakan oleh pakar komunikasi, tetapi komunikasi simbol selalu mewarnai kehidupan masyarakat terutama dalam menjalankan keyakinan dan budaya. (Morissan, 2013: 110113).

Semiotika menurut Berger memiliki dua tokoh, yakni Ferdinand De Saussure dan Charles Sander Peirce. Kedua tokoh tersebut mengembangkan ilmu semiotika secara terpisah dan tidak mengenal satu sama lain. Saussure di Eropa dan Peirce di Amerika Serikat. Latar belakang keilmuan Saussure adalah linguistik, sedangkan Peirce adalah filsafat. Saussure menyebut ilmu yang dikembangkannya semiology. Semiologi menurut Saussure didasarkan pada anggapan bahwa selama perbuatan dan tingkah laku manusia membawa makna atau selama berfungsi sebagai tanda, harus ada dibelakangnya sistem pembedaan dan konvensi yang memungkinkan makna itu.
Dimana ada tanda disana ada sistem. Sedangkan Peirce menyebut ilmu yang dibangunnya Semiotika. Bagi Peirce yang ahli filsafat dan logika, penalaran manusia senantiasa dilakukan lewat tanda. Artinya, manusia hanya dapat bernalar lewat tanda. Dalam pikirannya, logika sama dengan semiotika dan semiotika dapat diterapkan pada segala macam tanda. Dalam perkembangan selanjutnya, istilah Semiotika lebih popular dari pada semiologi. (Tinarbuko, 2008:52).

Kebudayaan merupakan sebuah sistem dari konsep-konsep yang diwariskan dan diungkapkan dalam bentuk-bentuk simbolik. Memperkembangkan pengetahuan tentang kehidupan dan bersikap terhadap kehidupan ini. Di satu sisi, simbol terbentuk melalui interaksi sosial yang dinamis, kemudian diwariskan secara historis, yang bermuatan nilai-nilai. Di sisi lain simbol merupakan acuan wawasan, memberi petunjuk bagaimana warga budaya tertentu menjalani hidup, dalam pesan komunikasi dan representasi realitas sosial. (Sobur,2004: 178). Dalam budaya, manusia pada umumnya selain pelaku seni, juga adalah penikmat seni. "Dalam seni teater, berbagai lakon yang melandasi penciptaan seni dikemas dengan baik sehingga mudah dinikmati dan disimak untuk mengisi wawasan berpikir.

Tari Baris Keraras ini tarikan oleh seorang pemuda laki-laki, Tarian ini hanya ditarikan oleh satu orang dengan atribut yang berbeda dari Tari Baris pada umumnya. Yakni menggunakan pakian poleh, awir Keraras dab nenbawa senjata berupa keris yang terbuat dari adonan sate, dan menggunakan hiasan daging babi sebagai gelungan, dan urutan babi sebagai kalung dan gelang kana. Dalam pementasan Tari Baris Keraras memiliki pakem dan gerak tari yang unik dari pada Tari Baris secara umum dipentaskan di pura yaitu mulai dari gerak Tari dan penabuhnya. Iringan tabuh Tari Baris Keraras ini diiringi dengan gambelan vokal. 
Semiotika komunikasi pada pementasan Tari Baris Keraras dalam upacara Aci Tulak Tunggul menjelaskan tanda-tanda, gerakan, simbol dan fungsi yang terdapat dalam Tari Baris Keraras dalam upacara aci Tulak Tunggul di Pura Taman Ayun.

\section{METODE PENELITIAN}

Jenis dan pendekatan dalam penelitian ini mempergunakan metode kualitatif.Lokasi penelitian bertempat di Pura Taman Ayun, Desa Adat Mengwi, Kecamatan Mengwi, Kabupaten Badung.Penentuan informan mempergunakan teknis snowball sampling.Jenis dan sumber data yang dipergunakan adalah kualitatif dan sumber data yang dipergunakan berupa data primer dan data sekunder. Instrumen penelitian mempergunakan Camera Digital danTape Recorder, inti Instrumen peneliti adalah peneliti itu sendiri. Teknik pengumpulan data yang dipergunakan seperti : observasi, wawancara, studi kepustakaan. Teknik analisis data dilakukan dengan beberapa tahapan seperti : reduksi, penyajian data, dan penarikan kesimpulan. Teknik penyajian hasil penelitian dilakukan dengan metode deskriptif.

\section{HASIL DAN PEMBAHASAN}

\section{Eksistensi Tari Baris Keraras dalam Upacara Aci Tulak Tunggul di Pura Taman Ayun Mengwi}

Seni tari merupakan salah satu bagian dari kehidupan masyarakat Bali yang mayoritas beragama Hindu. Tari sakral yang biasa dipakai mengiringi upacara yadnya, Tari Baris Keraras ini dipentaskan untuk mengiringi rangkian upacara piodalan di Pura Taman Ayun yang di sebut dengan upacara Aci Tulak Tunggul. Salah satu tari sakral yang masih banyak dipentaskan dalam rangkaian upacara keagaaman dan juga sering dipertunjukan sebagai kepentingan hiburan adalah Tari Baris. Diantara sekian banyak Tari Baris baik Baris wali maupun Baris bebalihan, terdapat salah satu tari Baris Wali yang tidak dimiliki oleh daerah manapun kecuali daerah Mengwi. Tari ini dinamakan Tari Baris Keraras. Tari ini merupakan salah satu jenis Tari Baris wali yang masih tetap dijaga kelestariannya hingga kini. Tari Baris Keraras biasanya dipentaskan saat Piodalan di Pura Taman Ayun Mengwi.

Beranjak dari peristiwa tersebut setiap ada upacara di Pura Taman Ayun dilaksanakan upacara pakelem dengan diiringi tarian yang dibawakan oleh para pemuda (laki-laki) dengan berpakian Keraras (daun pisang kering) dengan gelungan daun pelapah pisang yang dihiasi rebasan, sate lilit, kalung urutan, senjata sate yang dibentuk seperti keris, kemudian disebut dengan Tari Baris Keraras. Sebelum upacara ini dilaksanakan, selalu terjadi peristiwa orang tenggelam di kolam Pura Taman Ayun dan sawah yang mendapat pengairan dari kolam Taman Ayun selalu gagal dan terserang hama. Pementasan Tari Baris Keraras dalam upacara Aci Tulak Tunggul merupakan pengorbanan suci yang dilakukan oleh umat Hindu dan ditujukan kepada Tuhan Yang Maha Esa, maksud dari melakukan upacara Aci Tulak Tunggul adalah untuk menyatakan rasa terima kasih kehadapanNya atau kepada seluruh manifestasiNya. Koetjaraningrat, (1980: 256) yang menjelaskan bahwa upacara biasanya dipergunakan bermacam-macam sarana dan peralatan seperti tempat suci, dan tarian sakral.

Prosesi pelaksnaan pementasan Tari Baris Keraras dalam upacara Aci Tulak Tunggul, penari akan mempersiapkan diri terlebih dahulu, seperti menghias muka dan memasang atribut yang digunakan. Pelaksanaan upacara Aci Tulak Tunggul, tepatnya pada hari Anggara Kasih Medangsia pada hari piodalan di Pura Taman Ayun. Sebelum dimulai akan diawali dengan matur piuning terlebih dahulu di uatama mandala (jeroan) Pura Taman Ayun dengan sarana upakara daksina pejati, dengan tujuan 
memohon maklum kehadapan beliau bahwa Ida Pengelingsir Puri Ageng Mengwi akan melaksanakan upacara Aci Tulak Tunggul (mulang pakelem) di kolam pura Taman Ayun.

Upacara matur piuning yang dilakukan oleh pemangku dan beberapa krama subak, dan juga ikut serta seorang penari baris Keraras yang akan pentas dalam pelaksanaan upacara Aci Tulak Tunggul di pelinggih empelan, dan didampingi oleh Pengelingsir Puri Ageng Mengwi. Pada saat matur piuning, pemangku juga nunas tirta (kekuluh luhur) kemudian dibawa ke jaba di pelinggih empelan dimana upacara Aci Tulak Tunggul dilaksanakan. Acara matur piuning yang dilakukan di jeroan pura Taman Ayun.

\section{Semiotika Komunikasi Pementasan Tari Baris Keraras dalam Upacara Aci Tulak Tunggul di Pura Taman Ayun}

Tari Baris Keraras. Tanda-tanda yang bisa dilihat pada saat Tari Baris Keraras memiliki makna bahwa kekuatan dari penari Baris Keraras akan semakin kuat bersatu dengan Ida Bhatara sane merasuk ke badan penari tersebut. Demikian juga gerak Tari Baris Keraras menunjukan betapa kuat dan hebatnya Baris Keraras ngiringan pekayu Ida Bhatara yang oleh masyarakat setempat diyakini sebagai kekuatan Tuhan yang akan mampu membuat masyarakatnya Desa Mengwi dilindungi dari berbagai musibah, baik masyarakatnya maupun persawahan yang ada di Desa Mengwi dan menerima anugrah kesuburan untuk persawahan dan air yang akan dipergunakan oleh masyarakat Desa Mengwi untuk irigasi sawahnya dan kebutuhan masyarakat setempat.

Jika semua tanda yang nampak maupun yang dirasakan oleh seluruh masyarakat dan penonton adalah suatu bentuk komunikasi yang tidak akan pernah bisa lepas dari adanya visual dan verbal. Visual ditandai dengan berbagai macam simbol-simbol diantaranya kostum, properti, hiasan dan upakara yang dipergunakan pada saat pementasan Tari Baris Keraras yang langsung bisa dilihat oleh seluruh penonton yang hadir dalam ritual tersbut. Verbal ditandai dengan lisan maupun tulisan, semua benda sakral berupa Baris Keraras dengan fungsinya masing-masing adalah gugun tuwon, yang tidak tertulis tetapi sangat diyakini oleh masyarakat.

Terlaksananya upacara Aci Tulak Tunggul tentu didasari atas beberapa alasan yang dapat menumbuhkan keyakinan umat terhadap sebuah upacara yang mereka lakukan. Berbagai kegiatan yang nampak yang terangkum sedemikian rupa yang dilakukan oleh masyarakat desa Mengwi jelas memiliki latar belakang tertentu dipadukan dengan ide-ide dan kejadian historis lainya. Perpaduan ide-ide, yang dipadukan dengan kronologi historis membuat Upacara Aci Tulak Tunggul memiliki keunikankeuniakan tersendiri dibandingkan dengan berbagai jenis upacara lainnya. Hal tersebut diyakini oleh umat sehingga keberadaanya tetap terjaga hingga kini. Bahkan menjadi sebuah kebudayaan yang tertuang ke dalam bentuk sebuah upacara. Diperjelas lagi dengan meminjam penpar dari Preusz dalam (Donder, 2005: 78) yang menyatakan bahwa manusia beranggapan bahwa dengan dengan ritus itu akan dapat mencapai tujuan hidupnya baik yang bersifat material maupun spiritual. Pusat dari tiap sistem religi dan kepercayaan di Dunia adalah ritus dan upacara.

Beranjak dari peristiwa tersebut setiap ada upacara di Pura Taman Ayun dilaksanakan upacara Pakelem dengan diiringi tarian yang dibawakan oleh para pemuda (laki-laki) dengan berpakian keraras (daun pisang kering) dengan gelungan daun pelapah pisang yang dihiasi rebasan, sate lilit, kalung urutan, senjata sate yang kemudian disebut dengan baris Keraras. Sebelum upacara ini dilaksanakan, selalu terjadi peristiwa yang tidak sesuai dengan akal budi manusia seperti ada orang tenggelam di kolam 
Pura Taman Ayun dan begitu pula persawah yang berada di subak Bukti Batan Badung pengairannya tidak bagus dan selalu gagal panen karena terserang seperti tikus, walang sangit, dan wereng.

Pembendaharaan gerak Tari Baris Keraras (1). Pepeson, yaitu geraknya adalah gerakan Nayog sebanyak sepuluh kali. (2). Pengadeng atau pengawak, yaitu geraknya adalah angkat kaki kanan, angkat kaki kiri, nanjek dan seledet. Gerakan ini dilakukan sebanyak lima kali yaitu arah timur, selatan, barat, utara, dan terakhir di tengah gerakan ini disebut dengan gerakan ngider bhuana. (3). Penutup atau pekaad yaitu gerakan adalah Nayog yang dilakukan sebanyak enam kali. Semiotika gerak yang terkandung dalam Tari Baris Keraras adalah tersirat ajakan, imbauan untuk melestarikan alam semesta agar tetap terjaga, terjauh dari pengaruh luar yang bersifat negatif, dalam gerakan Tari Baris Keraras melambangkan gerakan Ngider Bhuana untuk menyeimbangkan Bhuana Agung dan Bhuana Alit.

Penjelasan atribut Tari Baris Keraras ini mengandung arti yang penuh makna yaitu : (1) Gelungan Tari Baris Keraras yang terbuat dari pelapah pisang dan hiasannya dipergunakan dari dagang babi dan kulit babi dengan berbagai bentuk senjata ngider bhuana merupakan lambang bunga dan buah hasil dari kesuburan tanah pertanian. (2) Hiasan muka dipergunakan Kapur Sirih (Pamor) melambangkan keseimbangan alam semesta. (3) Kalung dan gelang kana terbuat dari Urutan Babi merupakan lambang ular, di mana ular ini diyakini sebagai binatang penghusir hama di sawah seperti contohnya tikus, agar padi dapat tumbuh dengan baik tidak dimakan oleh tikus. (4) Keris yang terbuat dari adonan sate merupakan lambang dari unsur purusha atau laki-laki, karena diyakini bahwa laki-lakilah yang menjadi tulang punggung keluarga dan dapat memberikan kehidupan yang sejahtera bagi semua anggota keluarga. (5) Daun Pisang Kering (Keraras) merupakan lambang hutan, yang bermakna bahwa kehidupan petani tidak bisa terlepas dari hutan, karena hutan merupakan sumber mata air yang akan mengairi sawah-sawah petani, dan akan nantinya memberikan kesuburan pada lahan pertanian.seperti contohnya air dari Puncak Mangu yang mengairi persawahan di Subak Bukti Batan Badung. (6) Kain Poleng Kain Poleng memiliki arti penting dan sakral dalam kehidupan masyarakat di Bali memiliki maknai Rwa Bhineda, yang artinya representasi dua sifat yang berbeda atau bertolak belakang, digambarkan lewat warna hitam dan putih. Konsep ini melambangkan keseimbangan alam seperti adanya atas dan bawah, kanan dan kiri.

Makna pada kain poleng tidak hanya terdapat pada motifnya saja, tetapi pada sososk yang mengenakannya dalam upacara atau ritual tertentu. Kain poleng juga lekat dengan kehidupan religius umah Hindu di Bali. Dalam kesenian tradisional Bali, kain poleng digunakan pada berbagai seni tari, contohnya seperti pakian atau kostum yang dipergunakan oleh Tari Baris Keraras.

\section{Implikasi Pementasan Tari Baris Keraras dalam Upacara Aci Tulak Tunggul di Pura Taman Ayun}

Pementasan Tari Baris Keraras dalam Upacara Aci Tulak Tunggul, yang dapat diamati dari simbol dan interkasi dari tindakan masyarakat. Implikasi dari pelaksanaan Pementasan Tari Baris Keraras dalam Upacara Aci Tulak Tunggul, mengarah pada, implikasi komunikasi, implikasi sosial budaya, implikasi implementasi Tri Hita Karana, implikasi keseimbangan bhuana agung dan bhuana alit, implikasi ekonomi dan implikasi sosiologi 


\section{a. Implikasi Komunikasi}

Komunikasi simbol pada hakekatnya adalah suatu bentuk komunikasi nonverbal yaitu komunikasi yang menggunakan pesan- pesan nonverbal. Istilah nonverbal biasanya digunakan untuk melukiskan atau menggambarkan semua peristiwa diluar kata-kata terucap dan tertulis. Secara teoritis komunikasi nonverbal dan komunikasi ini saling berhubungan satu sama lain.

Manusia dalam mewujudkan rasa bhaktinya itu tidak akan merasa puas hanya dengan mengucapkan tanpa dinyatakan bhaktinya itu (Dedy, 2007: 214). Semua perasaan dan ucapan itu dilahirkan dalam bentuk nyata yaitu dalam bentuk tari, sehingga pikiran dan perasaan yang abstrak itu terlukis dalam bentuk nyata kedalam bentuk atau gerak tari yaitu Tari Baris Keraras. Pada pementasan Tari Baris Keraras di Pura Taman Ayun terlihat adanya makna keindahan sebagai akibat rasa bhakti dan rasa cinta manusia dalam menghubungkan diri ke hadapan Ida Sang Hyang Widhi Wasa.

\section{b. Implikasi Sosial Budaya}

Pementasan Tari Baris Keraras dalam Upacara Aci Tulak Tunggul juga memberikan ide-ide atau konsep dasar oleh beberapa kalangan seniman yang ada di daerah Mengwi, termasuk juga di Kabupaten Badung. Upacara Aci Tulak Tunggul yang diselenggarakan di pura Taman Ayun, banyak tertuang dalam berbagai kebudayaan dalam bentuk kesenianbaik berupa seni tari dan tabuh utamanya oleh Kalangan pemuda yang ada di daerah Mengwi seperti yang dinyatakan oleh Pengelingsir Puri Ageng Mengwi. implikasi kepada kebudayaan di daerah mengwi dalam berbagai bentuk kesenian, yang sering dipentaskan dalam beberapapragmen di berbagai kegiatan festival yang ada di Bali.
Realita di lapangan yang menunjukan bahwa, para generasi muda yang didukung oleh tetua masyarakat termasuk juga Pengelingsir Puri Ageng Mengwi, secara aktif menumbuhkan inisiatif, dan inovasi dalam berkesenian. Sehingga Pementasan Tari Baris Keraras dalam Upacara Aci Tulak Tunggul ini banyak tertuang dalam berbagai karya seni. Hal ini memeberikan implikasi kepada masyarakat untuk mengkonservasi kebudayan yang mereka miliki dan terintegrasi dengan kehidupan sosial dalam berkesenian.

\section{c. Implikasi Sosiologis}

Pementasan Tari Baris Keraras dalam Upacara Aci Tulak Tunggul ini memerlukan banyak tenaga atau pengayah agar semuanya dapat berjalan dengan lancar yang dimulai dari pembuatan banten dan sarana-sarana upacara lainnya termasuk juga penabuh yangmengiringi Tari Baris Keraras yang terdiri dari beberapa pemuda desa Mengwi. Persepsi masyarakat Desa Adat Mengwi dalam membuat sarana keagamaan mempunyai prinsip kerja atas dasar tulus ikhlas. Berbagai aktifitas keagamaan dilakukan secara gotong royong dilandasi dengan asas kekeluargaan, kebersamaan (saling asah asaih asuh).

Keberadaan Pementasan Tari Baris Keraras dalam Upacara Aci Tulak Tunggul dianggap sangat penting dalam upacara piodalan di Pura Taman Ayun, karena dapat menumbuhkan rasa kebersamaan dan rasa solidaritas yang tinggi antar masyarakat Desa Adat Mengwi. Melalui palaksanaan upacara Aci Tulak Tunggul mampu menjalin kekeluargaan bagi masyarakat desa Mengwi dan sekelilingnya di dalam persiapan pelaksaan upacara yang dilakukan secara ngayah. Ngayah merupakan karma utama karena didalamnya ada nilai sosial untuk menumbuhkan rasa kasih antar sesama manusia, maupun rasa bhakti pada Tuhan. 


\section{d. Implikasi Tri Hita Karana}

Tri Hita Karana memang merupakan sebuah konsep yang luhur yang diteruskan oleh leluhur kita di masa lalu, untuk membangun masyarakat sejahtera dalam kehidupan sekala maupun niskala. Adapun unsur-unsur Tri Hita Karana ini meliputi : (1) Hubungan manusia dengan Tuhan yang disebut dengan Parhyangan, (2) Hubungan manusia dengan sesamanya yang disebut dengan Pawongan dan (3) Hubungan manusia dengan alam lingkungannya disebut dengan Palemahan. Penerapan Tri Hita Karana dalam kehidupan umat Hindu di Bali dapat dijumpai dalam perwujudan upacara yajña yang dilakukan baik pada hari-hari tertentu maupun setiap hari. Seperti halnya umat hindu yang berada di daerah Mengwi yang tetap melestarikan sebuah Pementasan Tari Baris Keraras dalam Upcara Aci Tulak Tunggul.

Budaya yang berfungsi untuk mempertahankan implikasi Tri Hita Karana, karena keyakinan ini berfungsi untuk mempersembahkan hasil panen untuk menunjukan rasa syukur kehadapan Ida Sang Hyang Widhi Wasa atas segala rahmat yang diberikan kepada para petani. Jika dilihat implementasi Tri Hita Karana pada upacara ini, akan kita bahas satu persatu mulai dari parhyangan, pawongan, dan palemahan.

\section{e. Implikasi Keseimbangan Bhuana Agung dan Bhuana Alit}

Bhuwana Agung terdiri atas dua kata, yaitu kata "Bhuwana" yang artinya dunia, alam, loka dan jagat dan kata "Agung" berarti besar atau raya. Jadi, dari pe nggabungan kata-kata tersebut Bhuwana Agung berarti dunia yang besar atau lebih dikenal dengan sebutan alam semesta. Nama lain dari alam semesta adalahmakrokosmos, sedangkan Bhuwana Alit adalah dunia kecil yang unsur- unsurnya. Pementasan Tari Baris Keraras dalam Upacara Aci Tulak Tunggul yang dilaksanakan setiap piodalan di Pura Taman Ayun ini, sejenis dengan upacara danu kertih yang sering dilaksanakan oleh umat Hindu di Bali.

Danu Kertih merupakan suatu upaya unttuk menjaga kelestarian sumber- sumber air tawar di daratan seperti mata air, sungai, danau dan lain-lain. Secara sekala Danu Kertih kita laksanakan dengan menghormati, menjaga kelestarian dan kealamian sumber-sumber air tawar seperti danau, berbagai sumber mata air dan sungai. Agar tidak rusak atau tercemar perilaku yang tidak terpuji pada sumber-sumber air tawar sebagai salah satu unsur alam yang paling menentukan kehidupan di bumi ini. Secara niskala Danu Kerti kita laksanakan dengan melaksanakan berbagai upakara yang terkait dengan menjaga kesucian-kelestarian sumber-sumber air tawar, sedangkan secara niskala, serta melestarikan pura-pura beji dan ulun danu.

Pementasan atau kegiatan keagamaan kerap dilaksanakan di beberapa sumber air tawar dalam bentuk sebuah yadnya. Hal ini bertujuan untuk menjaga vibrasi energi positif pada sumber-sumber air tawar. Demikian pula halnya dengan pelaksanaan Pementasan Tari Baris Keraras dalam Upacara Aci Tulak Tunggul adalah sebuah upacara mulang pakelem yang dilakukan di kolam pura Taman Ayun dengan tujuan untuk melestarikan keseimbangan ekosistem air yang digunakan untuk sistem irigasi oleh krama Subak Bukti Batan Badung. Pekaseh Subak Bukti Batan Badung.

\section{f. Implikasi Ekonomi}

Pementasan Tari Baris Keraras dalam Upacara Aci Tulak Tunggul sangat berpengaruh terhadap perkembangan ekonomi masyarakat khususnya di daerah Mengwi. Upacara ini yang sesungguhnya berfungsi untuk memohon kesuburan lahan pertanian yang ada di mengwi. Apabila upacara ini tidak dilaksanakan maka petani akan mengalami gagal panen. Ketika Petani mengalami gagal panen, maka sumber 
daya alam yang bisa didapatkan akan sedikit. Hal inilah mempengaruhi perkembangan ekonomi masyarakat terhadap pelaksanaan Pementasan Tari Baris Keraras dalam Upacara Aci Tulak Tunggul.

Pelaksanaan budaya yang harus dilestarikan nampaknya memiliki implikasi yang berpengaruh terhadap perekonomian keluarga khususnya masyarakat Mengwi. Dengan menghandalkan hasil pertanian yang diperoleh oleh masyarakat mampu memberikan kesejahteraan keluarga para petani di daerah Mengwi. Ketika petani mengalami keberhasilan panen maka masyarakat dengan penuh keyakinan dan penuh rasa ikhlas menghaturkan hasil panen yang mereka dapatkan untuk dipersembahkan kehadapan Ida Sang Hyang Widhi Wasa sebagai manifestasinya Dewa Wisnu yang memberikan kesuburan bagi masyarakat.

\section{SIMPULAN}

Eksistensi Tari Baris Keraras dalam upacara Aci Tulak Tunggul adalah merupakan tradisi yang sudah diwariskan secara turuntemurun dari leluhurnya, setiap pelaksanakan upacara piodalan di Pura Taman Ayun selalu diikiuti dengan pementasan Tari Baris Keraras. Tradisi ini sangat diyakini oleh masyarakat Desa Adat Mengwi, masyarakat meyakini dengan pementasan Tari Baris Keraras ini dapat mendatangkan kesucian dan kesuburan dalam masyarakat Desa Adat Mengwi.

Semiotika merupakan pemahaman tentang tanda, makna, dan simbol dalam semiotika pementasan Tari Baris Keraras, semiotika upacara Aci Tulak Tunggul, semiotika Gerak Tari Baris Keraras, semiotika kostum dan properti yang dipergunakan Tari Baris Keraras.

Implikasi dari pementasan Tari Baris Keraras dalam upacara Aci Tulak Tunggul yang dapat disampaikan dalam penelitian ini diantaranya, (1) Implikasi Sosial Budaya yaitu segala hal yang diciptakan manusia dengan pikiran dan budinya dalam kehidupan, (2) Implikasi Sosiologis adalah rasa tulus ikhlas murni dan hati nurani bahwa segala sesuatu yang dibuat diusahakan semaksimal dan sebaik mungkin, (3) Implikasi Tri Hita Karana yaitu Hubungan manusia dengan Tuhan yang disebut dengan Parhyangan, Hubungan manusia dengan sesamanya yang disebut dengan Pawongan dan Hubungan manusia dengan alam lingkungannya, (4) Implikasi Keseimbangan Bhuana Agung dan Bhuana Alit merupakan makrokosmos dan mikrokosmos , (5) Implikasi Ekonomi merupakan suatu ilmu yang mempelajari aktivitas manusia yang berhubungan dengan produksi, konsumsi, dan distribusi dalam usaha pemenuhan kebutuhan hidup.

\section{DAFTAR PUSTAKA}

Afwadzi, B. (2014). Teori Semiotika Komunikasi Hadis Ala Umberto Eco. Mutawatir: Jurnal Keilmuan Tafsir Hadith, 4(2), 179-210.

Bandem, I Made. 1976. Baris Dance. Denpasar: Serba Guna Press

Bungin, Burhan. 2003. Metodologi Penelitian Kualitatif, Aktualisasi Metodologi ke arah Ragam Varian Kontemporer. Jakarta: Raja Grafindo Persada.

Danu Tirta, I Made. 2019. Kontruksi Ideologi Lokal Pura Peninggal Di Desa Pakraman Gempinis. IHDN. Denpasar.

Dedy Nur Hidayat. 2007. Pengantar Komunikasi Massa. Jakarta : PT Raja Grafindo Persada.

Effendy, Onong Uchjana. 2002. Ilmu Komunikasi Teori Dan Praktek. Bandung: PT Remaja Rosdakarya.

Geria, I Wayan, 2007. Transformasi Kebudayaan Bali: Memasuki Abad XXI. Surabaya: Paramita

Gorda, Ngurah. 1990. Metodologi Pendidikan Ilmu Sosial Pendekatan Praktis. Denpasar: Undiknas 
Sobur, Alex. 2004. Semeotika Komunikasi.

Cetakan kedua.Bandung : Remaja

Rosdakarya

Koentjaraningrat.1981. Beberapa Pokok Antropologi Sosial. Jakarta : Rineka Cipta.

Koentjaraningrat. 1982. Antropologi I. Jakarta:

Djambatan 